\title{
Laporan Kasus: Anestesi Blok Peribulbar pada Pasien dengan Gagal Jantung Kongestif yang Dilakukan Enukleasi
}

\author{
Muhamad Adli, Caroline Wullur \\ Pusat Mata Nasional Rumah Sakit Mata Cicendo
}

\begin{abstract}
Abstrak
Seorang pria berusia 73 tahun datang ke Instalasi Gawat Darurat Pusat Mata Nasional Rumah Sakit Mata Cicendo pada bulan November 2018 dengan keluhan nyeri mata yang mengeluarkan darah dan disertai dengan keluhan sesak. Pemeriksaan mata menunjukkan prolaps okuli dan direncanakan untuk dilakukan enukleasi. Ahli kardiologi mendiagnosis dengan hypertensive heart disease, congestive heart failure functional class IV, moderate mitral regurgitation, moderate aortic regurgitation. Laporan kasus ini bertujuan memaparkan keberhasilan tatalaksana anestesi pada pasien usia lanjut dengan gagal jantung kongestif yang dilakukan enukleasi dalam blok peribulbar. Teknik blok peribulbar dipilih agar tidak memperberat masalah kardiovaskular serta untuk meminimalisir depresi kardiak. Teknik ini dilakukan dengan menyuntikkan obat anestesi lokal levobupivakain 0,5\% pada inferotemporal, medial kantus, dan superonasal. Operasi berlangsung tanpa keluhan nyeri dan fluktuasi hemodinamik yang signifikan. Paskaoperasi pasien sadar penuh dengan skala nyeri NRS 60 menit paska operasi 0 . Hal ini menunjukkan bahwa teknik anestesi blok peribulbar memberikan hasil memuaskan pada tindakan enukleasi.
\end{abstract}

Kata kunci: Blok peribulbar, enukleasi, gagal jantung kongestif, prolaps okuli

\section{Enucleation under Peribulbar Block Anesthesia in Patients with Congestive Heart Failure: A Case Report}

\begin{abstract}
A 73-year-old male patient was presented to the emergency department of the National Eye Center Cicendo Hospital with a painful and bloody eye as well as shortness of breath. Eye examination revealed ocular prolapse and patient was scheduled for enucleation. The cardiologist diagnosed the patient with hypertensive heart disease, congestive heart failure functional class IV, moderate mitral regurgitation, and moderate aortic regurgitation. Patient then underwent treatment for six days. This case report aimed to describe the successful management of anesthesia in elderly patients with congestive heart failure who underwent peribulbar block for enucleation procedure. To prevent further cardiac problems and to minimize the risk of cardiac depression in this patient, the anesthetic technique chosen was peribulbar block with the injection of local anesthetic drug levobupivacaine $0.5 \%$ at the inferotemporal, medial canthus, and superonasal. The surgary took place without complaints of intraoperative pain and without significant hemodynamic fluctuations. Postoperatively, the patient was fully conscious and sixty minutes postoperative pain scale (Numeric Rating Scale) in this patient was 0 . This shows that the peribulbar block anesthesia technique can provide satisfactory results for enucleation procedure.
\end{abstract}

Key words: Congestive heart failure, enucleation, ocular prolapse, peribulbar block

Korepondensi: Muhamad Adli, dr., SpAn. M. Kes, Departemen Anestesi Pusat Mata Nasional Rumah Sakit Mata Cicendo, Bandung, Jl. Cicendo No. 4 Bandung, Tlpn (022) 43212380,Email muhamad.adli.b@gmail.com 


\section{Pendahuluan}

Prosedur enukleasi pada umumnya dilakukan dalam anestesi umum dengan pemberian pelemas otot, hal ini dikarenakan enukleasi merupakan suatu tindakan operasi amputasi bola mata yang akan melibatkan manipulasi ekstensif pada otot mata sehingga berisiko menyebabkan refleks okulokardiak.

Refleks okulokardiak memiliki potensi morbiditas dan mortalitas yang signifikan. ${ }^{1}$ Refleks okulokardiak pada tindakan enukleasi dapat bermanifestasi sebagai aritmia termasuk bigemini, bradikardia, hingga asistol. ${ }^{1}$ Oleh karena itu, tindakan enukleasi merupakan tindakan yang berisiko tinggi pada pasien usia lanjut dengan permasalahan kardiovaskular berat.

Tindakan anestesi yang dilakukan pada pasien dengan permasalahan tersebut di atas sebaiknya tidak memperberat masalah jantung yang ada, yaitu tindakan yang memiliki efek depresi kardiovaskular dan pulmonal yang minimal seperti anestesi regional. Kelebihan tindakan anestesi regional jika dibanding dengan anestesi umum meliputi efek antiinflamasi yang lebih baik (respons stres yang lebih rendah) dan terutama efek depresi kardiopulmonal yang lebih rendah. ${ }^{2}$ Oleh karena itu, jika operasi dapat dilakukan dalam anestesi regional, maka anestesi regional menjadi pilihan utama pada pasien dengan penyakit jantung. ${ }^{3}$

Laporan pada kasus ini memaparkan keberhasilan tata laksana anestesi pada pasien usia lanjut dengan gagal jantung kongestif yang dilakukan enukleasi dalam blok peribulbar sebagai tindakan anestesi yang dipilih.

\section{Laporan Kasus}

Seorang laki-laki berusia 73 tahun datang ke Instalasi Gawat Darurat Pusat Mata Nasional RS Mata Cicendo Bandung pada bulan November 2018 dengan prolaps isi bola mata disertai keluhan sesak berat. Pasien tersebut diberikan analgetik dan dirujuk ke Departemen Kardiologi RSUP Dr. Hasan Sadikin. Ahli Kardiologi mendiagnosis pasien tersebut dengan hypertensive heart disease, congestive heart failure functional class IV, moderate mitral regurgitation ec. mitral prolapse, moderate aortic regurgitation, dan dilakukan perawatan selama 6 hari. Pasien diberikan terapi ramipril, bisoprolol, furosemid, atorvastatin, dan parasetamol.

Setelah keadaan umum membaik, pasien dijadwalkan untuk dilakukan enukleasi. Pasien dipersiapkan untuk dilakukan enukleasi dalam anestesi blok peribulbar. Pasien dipersiapkan dalam posisi head up $30^{\circ}$, tanda vital pasien menunjukkan tekanan darah 120/45 mmHg, laju nadi $60 \mathrm{kali} / \mathrm{menit}$ reguler, laju napas 17$19 \mathrm{kali} / \mathrm{menit}, \mathrm{SpO}_{2}$ 92\%-94\% dengan udara bebas, dan 97\%-99\% dengan $0_{2} 3 \mathrm{~L} / \mathrm{m}$ via nasal kanul dengan skala nyeri NRS 3.

Untuk memberikan kenyamanan, pasien diberikan fentanil $25 \mu \mathrm{g}$ intravena dan propofol $20 \mathrm{mg}$ intravena. Kondisi isi bola mata yang prolaps tidak memungkinkan untuk dilakukan penekanan setelah tindakan anestesi blok peribulbar. Oleh karena itu, dilakukan draping dan pemasangan spekulum untuk membantu penekanan area sekitar bola mata serta dilakukan penyuntikan pada tiga titik dengan harapan obat anestesi lokal dapat menyebar dengan rata hingga ke ruang intakonal. Anestesi blok peribulbar dilakukan dalam keadaan aseptik dengan menyuntikkan levobupivakain 0,5\% $3 \mathrm{~mL}$ pada inferotemporal, $3 \mathrm{~mL}$ pada medial kantus, dan $3 \mathrm{~mL}$ pada superonasal menggunakan jarum ukuran 23 Ga $32 \mathrm{~mm}$.

Diseksi dan reseksi otot ekstraokular dapat dilakukan dengan baik tanpa rasa nyeri dan perubahan hemodinamik yang bermakna. Namun, kemudian pada saat dilaksanakan pemasangan klem pada area nervus optikus, kepala pasien bergerak menandakan rasa tidak nyaman atau nyeri sehingga klem dilepas dan dilakukan penambahan infiltrasi anestesi lokal pada jarigan adiposa di sekitar nervus optikus dengan lidokain 2\%, serta ditambahkan propofol $30 \mathrm{mg}$, kemudian dilakukan kembali pemasangan klem pada nervus optikus. Pemotongan nervus optikus dilakukan tanpa keluhan nyeri dan perubahan hemodinamik yang bermakna. Operasi selesai dalam 40 menit. Kondisi pasien pascaoperasi 
sadar penuh dengan dengan skor Aldrette satu jam paskaoperasi 10, NRS 0, serta tidak terdapat mual muntah pascaoperasi. Pasien diberikan kombinasi analgetik pascaoperasi parasetamol dan ibuprofen per oral. Pada pasien ini tidak didapatkan phantom eye pain.

\section{Diskusi Kasus}

Enukleasi merupakan suatu tindakan operasi yang melibatkan pengangkatan seluruh bola mata dan sebagian dari nervus optikus. ${ }^{4}$ Enukleasi dilakukan pada pasien dengan mata buta yang sangat nyeri atau pasien dengan tumor intraokuler (misal: retinoblastoma, melanoma).,5 Prosedur ini pada umumnya dilaksanakan dalam anestesi umum dengan pemberian pelemas otot. Hal ini dikarenakan enukleasi adalah suatu tindakan operasi amputasi bola mata yang akan melibatkan manipulasi pada otot mata sehingga berisiko menyebabkan refleks okulokardiak. Refleks okulokardiak itu memiliki potensi morbiditas dan mortalitas yang signifikan. ${ }^{1}$ Refleks okulokardiak pada tindakan enukleasi dapat bermanifestasi sebagai aritmia termasuk bigemini, bradikardia, hingga asistol. ${ }^{1}$ Skala nyeri yang ditimbulkan pascaoperasi pada tindakan enukleasi, yaitu 3-4. ${ }^{5}$

Pada pasien ini didapatkan dua hal permasalahan, yaitu pasien usia lanjut dengan gagal jantung kongestif (CHF) sehingga tindakan enukleasi pada pasien ini memiliki risiko yang sangat tinggi. Gagal jantung kongestif adalah sindrom klinis kompleks yang ditandai dengan gangguan kinerja ventrikel, keterbatasan aktivitas fisik, insidensi aritmia ventrikel yang tinggi, dan harapan hidup yang lebih pendek. ${ }^{6}$ Gagal jantung kongestif merupakan salah satu penyakit yang umumnya terjadi pada pasien usia lanjut. ${ }^{7}$ Patofisiologi yang mendasarinya sangat bervariasi. Sekitar 50\% dari pasien yang menderita CHF didapatkan fraksi ejeksi ventrikel kiri menurun. ${ }^{7}$ Mortalitas pada periode perioperatif meningkat pada pasien dengan CHF, ini berlaku bagi operasi minor maupun mayor. ${ }^{7}$ Oleh karena itu, prosedur anestesi yang dipilih harus memiliki efek depresi kardiak yang minimal serta pemulihan yang cepat (fast track), misalnya dengan teknik anestesi blok.

Anestesi fast-track merupakan metode yang relatif lebih aman pada prosedur operasi mata bagi pasien usia lanjut. ${ }^{8}$ Obat-obatan kerja singkat seperti propofol, alfentanil, remifentanil, dan fentanil telah dipergunakan dengan hasil yang baik. ${ }^{8}$ Kombinasi propofol dan opioid telah terbukti efektif dalam memberikan analgesia dengan tingkat sedasi moderat bagi teknik anestesi blok regional pada mata. ${ }^{8}$

Teknik anestesi blok dan anestesi lokal mempunyai efek samping pada kardiovaskular atau pulmonal yang relatif lebih ringan bilamana dibanding dengan anestesi umum. ${ }^{2}$ Keuntungan tindakan anestesi regional jika dibanding dengan anestesi umum meliputi efek anti-inflamasi yang lebih baik (respons stres yang lebih rendah) dan efek kardiopulmonal yang lebih rendah. ${ }^{2}$ Oleh karena itu, jika operasi dapat dilakukan dalam anestesi regional, maka anestesi regional menjadi pilihan utama pada pasien dengan penyakit jantung. ${ }^{3}$ Pada pasien ini diputuskan untuk dilakukan tindakan enukleasi dalam anestesi blok regional dan sedasi ringan dengan pemberian propofol 20 mg dan fentanil $25 \mathrm{mcg}$.

Teknik anestesi secara lokal/regional pada operasi mata saat ini semakin populer. Teknik ini terutama dilakukan oleh ahli anestesi dengan teknik yang bervariasi mulai injeksi akinetik hingga teknik topikal non-akinetik. ${ }^{9}$ Setiap teknik memiliki profil risiko dan keuntungannya masing-masing, serta terbukti memberikan hasil yang baik jika dilakukan dengan benar. ${ }^{9}$ Pemilihan teknik anestesi regional pada operasi mata disesuaikan dengan jenis operasi, pilihan pasien, dan keadaan pasien. ${ }^{9,10}$ Teknik regional anestesi pada mata meliputi blok peribulbar, blok retrobulbar, dan blok subtenon.

Tantangan teknik blok pada luka mata terbuka seperti prolaps okuli pada pasien ini adalah sulitnya penatalaksanaan komplikasi perdarahan (bola mata tidak intak) karena pada prosedur tata laksana komplikasi tersebut diperlukan kompresi atau penekanan 
untuk menghentikan perdarahan. Komplikasi ini menjadi lebih sulit ditangani terutama jika perdarahan terjadi pada ruang intrakonal (retrobulbar). Oleh karena itu, pada pasien ini dipilih tindakan anestesi blok peribulbar untuk mengurangi risiko komplikasi perdarahan retrobulbar yang dapat mengakibatkan kegagalan anestesi blok tersebut.

Teknik blok peribulbar dilakukan dengan menyuntikkan obat anestesi lokal pada ruang ekstrakonal. Diperlukan volume obat anestesi lokal yang cukup besar agar distribusi obat dapat mencapai seluruh jaringan adiposa dan juga ruang intrakonal. ${ }^{11}$ Terdapat struktur utama (pembuluh darah dan nervus optikus) yang terletak di dalam ruang intrakonal, sehingga rentan terhadap risiko cedera jarum, termasuk nervus optikus dengan selaput meningeal, sebagian besar arteri, dan persarafan autonom, sensorik, dan motorik bola mata. ${ }^{11}$ Beberapa penulis mengusulkan untuk menghindari penempatan jarum pada ruang intrakonal (retrobulbar) dan lebih memilih untuk menempatkan jarum pada ruang ekstrakonal (peribulbar), teknik ini secara teori memiliki risiko yang lebih rendah. ${ }^{11}$

Pada pasien ini dilakukan penyuntikan obat anestesi lokal levobupivakain $0,5 \%$ pada tiga titik, yaitu inferotemporal, medial kantus, dan superonasal dengan volume masing-masing 3 mL. Namun demikian, diduga penyebaran obat anestesi lokal ke ruang intakonal tidak tercapai sempurna ditandai dengan gerakan kepala pasien pada saat pemasangan klem pada area nevus optikus. Oleh karena itu, diberikan suplementasi injeksi 1,5 mL lidokain $2 \%$ pada jaringan adiposa di sekitar nervus optikus.

Salah satu komplikasi yang dapat terjadi paskaenukleasi, yaitu phantom eye syndrome. Phantom eye syndome adalah sensasi nyeri pada daerah mata meskipun sebenarnya mata yang sakit tersebut telah diamputasi. Sindroma ini serupa dengan phantom limb pada kasus amputasi ektremitas. ${ }^{12,13}$ Nyeri pada Phantom eye syndrom dapat menghambat pemulihan pasien dan berpotensi menimbulkan nyeri kronis. Sama halnya dengan phantom limb, teknik anestesi regional sebelum tindakan operasi dapat mencegah timbul phantom eye pain paskaoperasi. ${ }^{13}$ Pada pasien ini tidak didapatkan phantom eye pain.

Teknik blok peribulbar terhadap pasien ternyata berhasil mempertahankan stabilitas hemodinamik selama operasi, menandakan depresi kardiovaskularyang minimal serta efek analgesi yang adekuat. Keberhasilan teknik ini juga ditandai dengan skala nyeri paskaoperasi yang rendah, tidak terjadi phantom eye syndrome, serta meminimalisir efek samping yang sering muncul pascaanestesi umum pada operasi mata seperti mual dan muntah paskaoperasi.

\section{Simpulan}

Teknik anestesi blok regional pada operasi enukleasi dapat menjadi pilihan yang lebih aman untuk dilakukan pada pasien dengan permasalahan sistemik yang berat. Teknik ini memungkinkan prosedur anestesi dengan tingkat depresi kardiopulmonal yang minimal serta pemulihan yang lebih cepat sehingga relatif lebih aman bagi pasien dan lebih efisien dari sisi biaya. Kombinasi anestesi regional dengan pemberian sedatif akan memberikan kenyamanan pada pasien sehingga dapat memberikan hasil yang memuaskan.

\section{Daftar Pustaka}

1. Ryder S, Lelli G. Factors influencing the oculocardiac reflex during enucleation. Investigative Ophthalmol Visual Sci. 2013;54(15):737.

2. Kettner S, Willschke $\mathrm{H}$, Marhofer P. Does regional anaesthesia really improve outcome? $\mathrm{Br} \mathrm{J}$ Anaesth. 2011;107(S1):i90-5.

3. Kaul TK, Tayal G. Anaesthetic considerations in cardiac patients undergoing non-cardiac surgery. Indian J Anaesth. 2007;51(4):280-6.

4. Jordan DR, Mawn L. Enucleation, Evisceration, and Exenteration. Dalam: Dunn JP, Langer PD, penyunting. Basic techniques of ophthalmic surgery. Edisi 
ke-1. San Francisco: American Academy of Ophthalmology; 2009. hlm. 305.

5. Callaway NF, Moshfeghi DM, Jaffe RA. Ophthalmic surgery. Dalam: Jaffe RA, penyunting. Anesthesiologist's manual of surgical procedures. Edisi ke-5. Philadelphia: Wolters Kluwer Health; 2014. hlm. 247.

6. Magner J, Royston D. Heart failure. Br J Anaesth. 2004;93(1):74-85.

7. Smit-Fun V, Buhre $\mathrm{W}$. The patient with chronic heart failure undergoing surgery. Curr Opin Anesthesiol. 2016;29(3):391-6.

8. Fang ZT. Anesthesia management of ophthalmic surgery in geriatric patients. California: American Academy of Ophthalmology Tersedia dari: https:// www.aao.org/Assets / 0985 ab3920 ce- $4779-9322$ - e 718972 edd 86 /635711977904770000/anesthesiamanagement-of-ophthalmic-surgery-ingeriatric-patients.pdf.
9. Jaichandran V. Ophthalmic regional anaesthesia: a review and update. Indian J Anaesth. 2013;57(1):7-13.

10. Anker R, Kaur N. Regional anaesthesia for ophthalmic surgery. BJA Educat 2017;17(7):221-7.

11. Ripart J, Nouvellon E, Chaumeron A. Regional anesthesia for eye surgery. Reg Anesth Pain Med. 2005;30(1):72-82.

12. Andreotti AM, Goiato MC, Pellizzer EP, Pesqueira AA, Guiotti AM, GennariFilho $\mathrm{H}$, dkk. Phantom eye syndrome: a review of the literature. Scient World J. 2014;2014:1-6.

13. Eker E, Macachor JD. Chronic ophthalmic pain and pain syndromes: causes and treatment. Dalam: Jaichandran VV, Chandra MK, Jagadeesh V, penyunting. Principles and practices of ophthalmic anesthesia. Edisi ke-1. New Delhi: Joypee Brothers; 2017. hlm. 359. 